\title{
Anomalous crystal packing of iptycene secondary diamides leading to novel chain and channel networks
}

\author{
Jye-Shane Yang, ${ }^{\mathrm{a}, *}$ Chia-Peng Liu ${ }^{\mathrm{a}}$ and Gene-Hsiang Lee ${ }^{\mathrm{b}}$ \\ ${ }^{a}$ Department of Chemistry, National Central University, Chung-Li 32054, Taiwan \\ ${ }^{\mathrm{b}}$ Instrumentation Center of National Taiwan University, Taipei 10660, Taiwan
}

Received 19 June 2000; revised 7 August 2000; accepted 10 August 2000

\begin{abstract}
The crystal structures of triptycene and pentiptycene secondary diamides $\mathbf{1}$ and $\mathbf{2}$ grown from methanol solutions are reported. In addition, the crystal structure of $\mathbf{1}$ from a toluene-methanol mixed solution was also determined. The molecular structures of $\mathbf{1}$ in both crystals are folded, and an anomalous hydrogenbonding chain motif is generated. On the other hand, the pentiptycene diamide $\mathbf{2}$ adopts an extended conformation, and the amide groups do not participate in any known amide-amide hydrogen-bonding patterns. Instead, interdigitated molecular stacking results in grid-like channels having a void volume of ca. $25-30 \%$ of the crystal. The potential of iptycene-derived building blocks in the design of new organic crystalline materials is thus demonstrated.
\end{abstract}
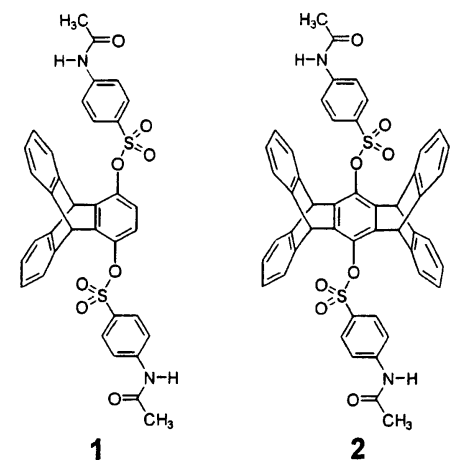

(C) 2000 Elsevier Science Ltd. All rights reserved.

The aromatic and three-dimensional iptycene scaffolds have recently demonstrated particular utility in the formation of new organic materials, including chemical sensors, ${ }^{1}$ liquid crystals, ${ }^{2}$ and molecular devices. ${ }^{3}$ On the other hand, in crystal engineering, ${ }^{4}$ taking advantage of such structural features in the design of novel supramolecular architectures has not been extensively

\footnotetext{
* Corresponding author. Tel: 886-3-4227402; fax: 886-3-4227664; e-mail: jsyang@rs250.ncu.edu.tw 
explored. ${ }^{5,6}$ In particular, the cavity-forming propensity of parent iptycenes ${ }^{7}$ in the solid state has not yet led to the development of iptycene-derived nanoporous materials. ${ }^{8}$ We report herein two novel supramolecular structures created by the iptycene secondary diamides $\mathbf{1}$ and $\mathbf{2}$. While the crystal packing of secondary diamides generally conforms to the tape or the sheet hydrogen-bonding motif, ${ }^{9}$ an anomalous chain motif is formed by the triptycene diamide $\mathbf{1}$. Moreover, an unexpected shortage of amide-amide hydrogen-bonding was found for the pentiptycene analogue 2. Instead, interdigitated molecular stacking generates two types of wide and parallel channels.

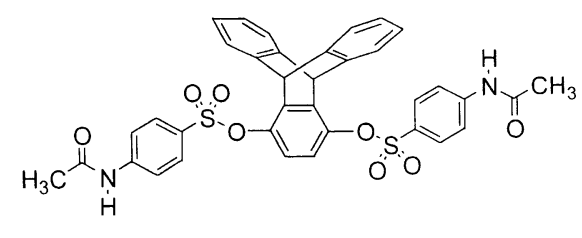

1

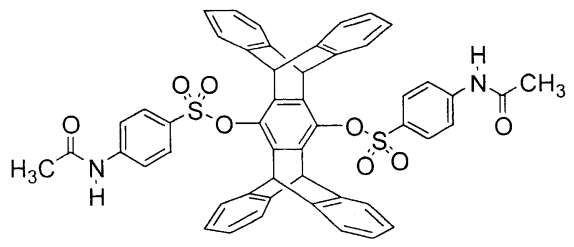

2

Diamides 1 and $\mathbf{2}$ were synthesized from the corresponding iptycene hydroquinones ${ }^{1,5}$ and the commercially available $N$-acetylsulfanilyl chloride under a standard $\mathrm{S}_{\mathrm{N}} 2$ reaction condition. ${ }^{10}$ Single crystals of both $\mathbf{1}$ and $\mathbf{2}$ were obtained from slow evaporation of the corresponding dilute methanol solutions at room temperature. ${ }^{11}$ In addition, the crystal structure of $\mathbf{1}$ grown from a toluene-methanol mixed solution was also determined.

The molecular structure of triptycene diamide $\mathbf{1}$ is folded, in which one flanking benzene ring (designated with $\mathrm{C}$ in Fig. 1(a)) of the triptycene group is in proximity to the two benzene groups (rings $\mathrm{A}$ and $\mathrm{B}$ ) of the $N$-acetylsulfanilyl substituents. The center-to-center ring distances of 4.2-4.5 $\AA$ and plane-to-plane dihedral angles of $27-50^{\circ}$ defined by the two benzene pairs (A-C and $\mathrm{B}-\mathrm{C}$ ) suggest a contribution of edge-to-face arene-arene interactions ${ }^{12}$ to the folded conformation. The folded conformation is further established by the formation of a 21-membered hydrogen-bonded ring, in which the $(\mathrm{N}) \mathrm{H} \cdots \mathrm{O}$ distances $(2.00 \AA)$ and the $\mathrm{N}-\mathrm{H} \cdots \mathrm{O}$ and $\mathrm{H} \cdots \mathrm{O}=\mathrm{C}$ angles (166 and $144^{\circ}$, respectively) conform to the values for optimum amide-amide hydrogen-bonding. ${ }^{13}$ Consequently, an anomalous diamide hydrogen-bonding chain motif is generated, leading to a novel supramolecular architecture looking like molecules in a tug-of-war (Fig. 1(b) and (c)). Since such a folded and chain structure is observed in both crystals from different solvents, it is probably the most stable form for $\mathbf{1}$ in the solid state. ${ }^{14}$ In addition, two aspects from the comparison of the two crystal structures of $\mathbf{1}$ are worth noting. First, the molecules of the two crystals are in an interesting relationship of a pseudo-mirror image because of the opposite hydrogen-bonding direction. Second, the packing of neighboring chains might be susceptible to the solvating conditions. While no solvent is included in the crystal from a methanol solution, channels running parallel to the hydrogen-bonding $(b)$ axis are formed in the other case. The channels are filled with solvent molecules in a $\cdots$ toluene, toluene, methanol, toluene, toluene, methanol $\cdots$ sequence (Fig. 1(c)), resulting in a 1:1:0.5 of diamide 1:toluene: methanol ratio.

Unlike the folded conformation of $\mathbf{1}$, the pentiptycene diamide $\mathbf{2}$ adopts an extended conformation, in which the $N$-acetylanilyl substituents are nearly planar and parallel (Fig. 2(a)). Furthermore, unlike the amide-amide hydrogen-bonding in $\mathbf{1}$, as well as other secondary diamides, the amide groups in $\mathbf{2}$ do not participate in any known hydrogen-bonding networks. $^{9,15}$ Evidently the bulk of pentiptycene moieties interferes with the normal modes of 
(a)

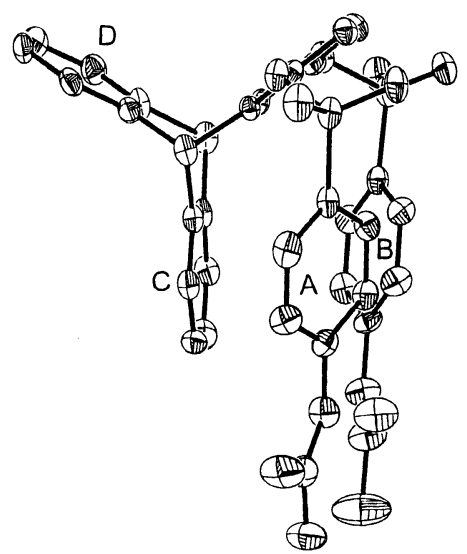

(b)
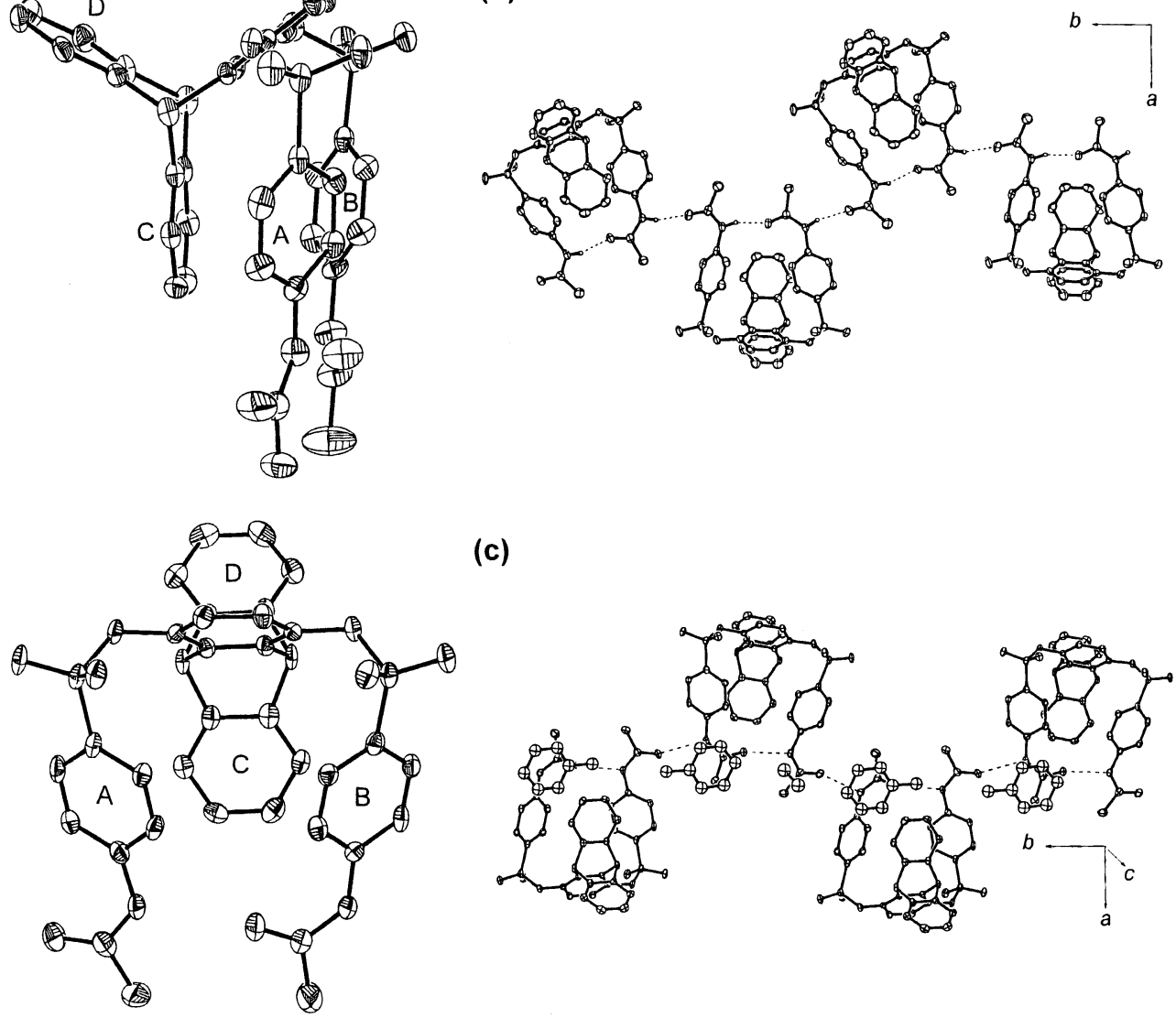

(c)

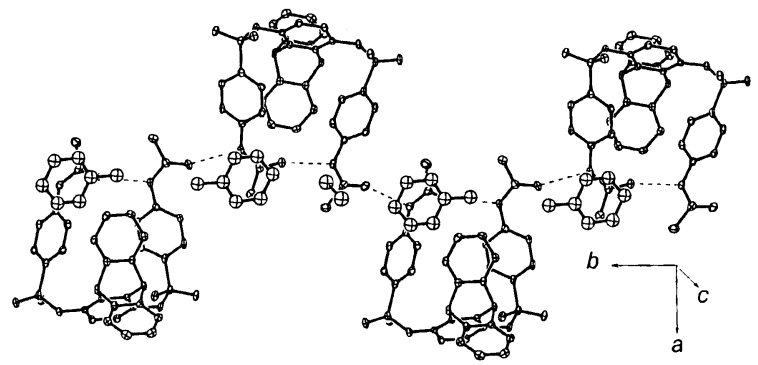

Figure 1. (a) Two views of the crystal structure of 1 from a toluene-methanol mixed solution with benzene rings labeled (A-D), and the hydrogen-bonding chain motif of the crystals from (b) a methanol and (c) toluene-methanol mixed solutions (solvent included)

diamide hydrogen-bonding. The crystal structure, thus, appears to be mainly controlled by molecular stacking interactions. First, an upright stacking of the pentiptycene groups along the $a$ axis leads to the formation of one-dimensional pillars with protruding benzene rings (Fig. 2(b)), which then interdigitates with two adjacent pillars forming zigzag two-dimensional pentiptycene walls (Fig. 2(c)). The final structure is accomplished by an interdigitated stacking of the $\mathrm{N}$-acetylsulfanilyl groups between adjacent walls (Fig. 2(a)), creating a novel grid-like channel network (Fig. 2(d)). A 1:6 diamide 2:methanol ratio results in the inclusion of as many as 24 methanol molecules per unit cell, and the void space of the two different channels is estimated to be $25-30 \%$ of the total crystal volume. ${ }^{16}$

In conclusion, our preliminary results have demonstrated the potential of iptycene-derived building blocks in the formation of new supramolecular architectures. Although further evidences are required to gain an insight into the nonbonded forces that govern the structures of 1 and 2, it appears that the steric and aromatic features of iptycene groups dominate the self-assembly of both diamides. Regarding the growing interest in the search of new oligomers or polymers that adopt well-defined secondary structures in solutions, as well as in the solid state, the folding behavior of diamide 1 may prove of value in the design of new 'foldamers'. ${ }^{17}$ 
(a)

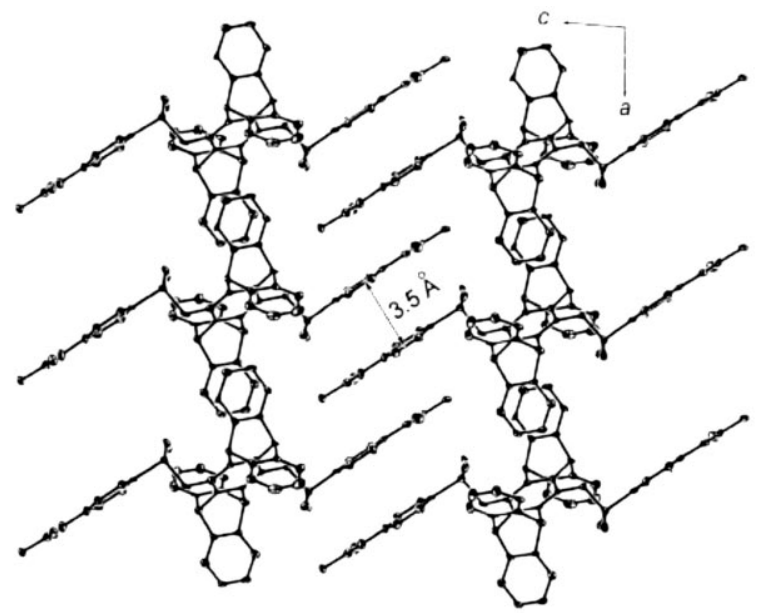

(b)

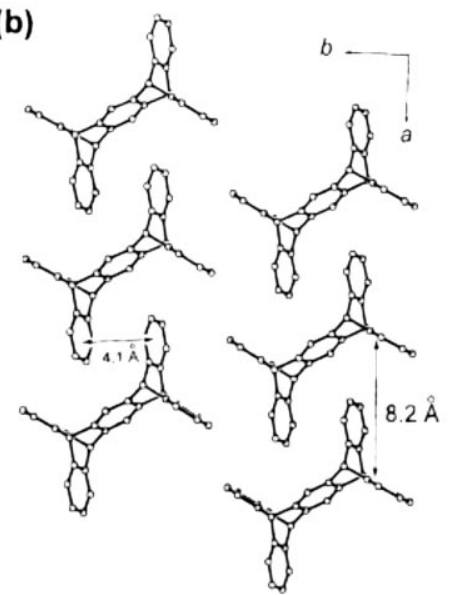

(c)

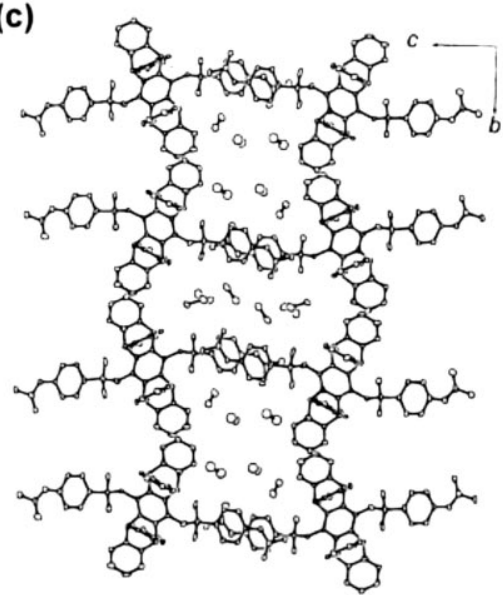

(d)

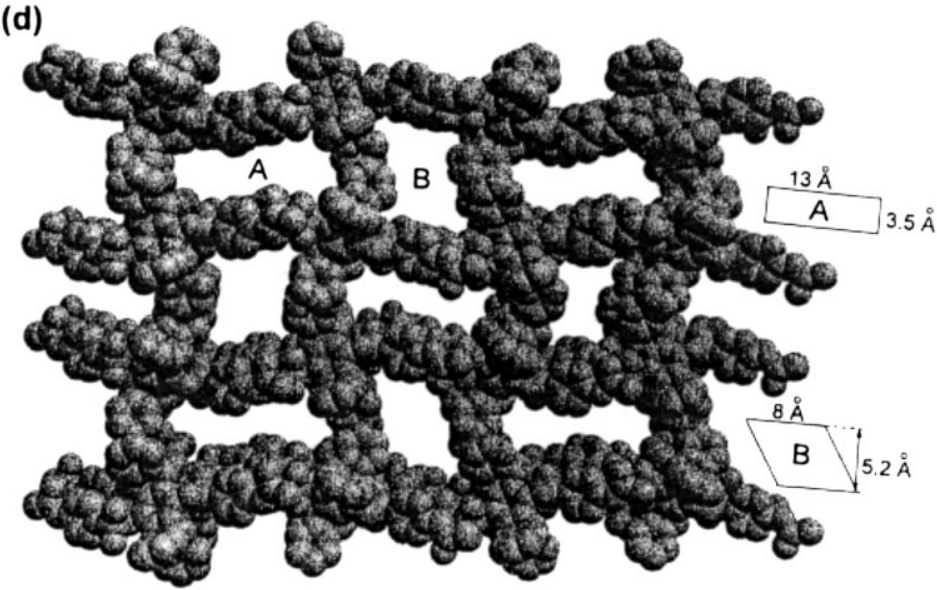

Figure 2. Crystal packing diagrams of $\mathbf{2}$ showing (a) the extended conformation and the stacking of $N$-acetylsulfanilyl substituents; (b) pentiptycene pillars; (c) the top view of zigzag pentiptycene walls and channels (solvent included), and (d) the effective sizes of channels by a space-filling model

Moreover, the amide functionalities accessible around the channels of diamide $\mathbf{2}$ might direct particular molecular recognition, leading to the formation of new organic clathrates. Further study of these two and other iptycene systems are ongoing in our laboratory.

\section{Acknowledgements}

Financial support for this research was provided by the National Science Council (NSC 89-2113-M-008-002).

\section{References}

1. (a) Yang, J.-S.; Swager, T. M. J. Am. Chem. Soc. 1998, 120, 5321. (b) Yang, J.-S.; Swager, T. M. J. Am. Chem. Soc. 1998, 120, 11864. 
2. Norvez, S. J. Org. Chem. 1993, 58, 2414.

3. Kelly, T. R.; De Silva, H.; Silva, R. A. Nature 1999, 401, 150.

4. (a) Desiraju, G. R. Crystal Engineering_-The Design of Organic Solids; Elsevier: New York, 1989. (b) Solid-State Supramolecular Chemistry: Crystal Engineering in Comprehensive Supramolecular Chemistry; MacNicol, D. D.; Toda, F.; Bishop, R.; Eds.; Pergamon: Exeter, 1996, Vol. 6.

5. Yang, J.-S.; Lee, C.-C.; Yau, S.-L.; Chang, C.-C.; Lee, C.-C.; Leu, J.-M. J. Org. Chem. $2000,65,871$.

6. Marc Veen, E.; Postma, P. M.; Jonkman, H. T.; Spek, A. L.; Feringa, B. L. Chem. Commun. $1999,1709$.

7. (a) Wilcox, C. F.; Roberts, F. D. J. Org. Chem. 1965, 30, 1959. (b) Bashir-Hashemi, A.; Hart, H.; Ward, D. L. J. Am. Chem. Soc. 1986, 108, 6675. (c) Venugopalan, P.; Bürgi, H.-B.; Frank, N. L.; Baldridge, K. K.; Siegel, J. S. Tetrahedron Lett. 1995, 36, 2419.

8. Examples of nanoporous architectures see: (a) Venkataraman, D.; Lee, S.; Zhang, J.; Moore, J. S. Nature 1994, 371, 591. (b) Endo, K.; Sawaki, T.; Koyanagi, M.; Kobayashi, K.; Masuda, H.; Aoyama, Y. J. Am. Chem. Soc. 1995, 117, 8341. (c) Bhyrappa, P.; Wilson, S. R.; Suslick, K. S. J. Am. Chem. Soc. 1997, 119, 8492. (d) Pedireddi, V. R.; Chatterjee, S.; Ranganathan, A.; Rao, C. N. R. J. Am. Chem. Soc. 1997, 119, 10867. (e) Evans, C. C.; Sukarto, L.; Ward, M. D. J. Am. Chem. Soc. 1999, 121, 320.

9. Lewis, F. D.; Yang, J.-S.; Stern, C. L. J. Am. Chem. Soc. 1996, 118, 12029 and references cited therein.

10. Spectroscopic data: $1\left(\mathrm{mp}=231^{\circ} \mathrm{C}\right.$ decomposed): ${ }^{1} \mathrm{H}$ NMR (DMSO-d $\left.6,200 \mathrm{MHz}\right): 2.09$ (s, 6H), 5.77 (s, $\left.2 \mathrm{H}\right), 6.68$ $(\mathrm{s}, 2 \mathrm{H}), 6.95(\mathrm{dd}, J=5.3$ and $3.2 \mathrm{~Hz}, 4 \mathrm{H}), 7.32(\mathrm{dd}, J=5.3$ and $3.2 \mathrm{~Hz}, 4 \mathrm{H}), 7.84(\mathrm{~s}, 8 \mathrm{H}), 10.50(\mathrm{~s}, 2 \mathrm{H}) \mathrm{ppm} ;{ }^{13} \mathrm{C}$ NMR (DMSO-d 6 , 50 MHz): 24.53, 47.73, 119.26, 120.74, 124.56, 125.64, 127.38, 130.05, 141.24, 142.31, 143.88, 145.55, 169.72 ppm; IR (KBr): 3264, 1671, 1590, 1536, 1408, $1181 \mathrm{~cm}^{-1}$; FAB-HRMS calcd for $\mathrm{C}_{36} \mathrm{H}_{28} \mathrm{~N}_{2} \mathrm{O}_{8} \mathrm{~S}_{2}$ $\left(\mathrm{M}^{+}\right)$680.1287, found 680.1271. $2\left(\mathrm{mp}=212.5-214^{\circ} \mathrm{C}\right):{ }^{1} \mathrm{H}$ NMR (DMSO-d $\left.6,200 \mathrm{MHz}\right): 2.20$ (s, 6H), 5.77 (s, 4H), $6.94(\mathrm{dd}, J=4.9$ and $3.2 \mathrm{~Hz}, 8 \mathrm{H}), 7.33(\mathrm{dd}, J=4.9$ and $3.2 \mathrm{~Hz}, 8 \mathrm{H}), 8.11(\mathrm{~d}, J=8.8 \mathrm{~Hz}, 4 \mathrm{H}), 8.44(\mathrm{~d}, J=8.8$ $\mathrm{Hz}, 4 \mathrm{H}), 10.69$ (s, 2H) ppm; ${ }^{13} \mathrm{C}$ NMR (DMSO-d 6 , $50 \mathrm{MHz}$ ): 24.63, 48.54, 119.68, 124.57, 125.56, 128.29, 130.35, 137.02, 139.23, 144.29, 145.88, 169.87 ppm; IR (KBr): 3399, 1684, 1597, 1522, 1457, $1167 \mathrm{~cm}^{-1}$; FAB-HRMS calcd for $\mathrm{C}_{50} \mathrm{H}_{37} \mathrm{~N}_{2} \mathrm{O}_{8} \mathrm{~S}_{2}\left(\mathrm{M}+\mathrm{H}^{+}\right)$857.1991, found 857.1974.

11. Data for the X-ray structures were recorded using a Siemens SMART/CCD diffractometer at $150 \pm 1^{\circ} \mathrm{K}$. The structures were refined using full-matrix least-squares on $F^{2}$. All the crystals are colorless, and the following are data for the crystal system, space group, unit cell parameters ( $\AA$ and degree), $Z, R_{1}$ and $w R_{2}(I>2 \sigma(I))$, and GOF. For 1 from methanol: monoclinic, $P 2_{1} / n, a=12.8237(1), b=18.9157(1), c=13.8409(2), \beta=102.649(1), 4,0.0554$, $0.1136,1.083$. For 1 from toluene-methanol mixed: monoclinic, $P 2_{1} / c, a=12.0157(3), b=19.0749(2), c=$ 17.5159(4), $\beta=103.137(1), 4,0.0960,0.1830,1.120$. For 2 from methanol: monoclinic, $P 2_{1} / c, a=8.2207(3)$, $b=21.6601(7), c=29.7746(8), \beta=93.764(1), 4,0.1722,0.3987,1.163$. (The high $R$ indices are attributed to the high volatile solvent content in the needle-type crystals.)

12. (a) Jorgensen, W. L.; Severance, D. L. J. Am. Chem. Soc. 1990, 112, 4768. (b) Hunter, C. A.; Sanders, J. K. M. J. Am. Chem. Soc. 1990, 112, 5525. (c) Linse, P. J. Am. Chem. Soc. 1992, 114, 4366.

13. Leiserowiz, L.; Tuval, M. Acta Crystallogr., Sect. B 1978, 34, 1230.

14. Results of our preliminary ${ }^{1} \mathrm{H}$ NMR analysis indicate that a folded conformation is also preferred in organic solutions.

15. MacDonald, J. C.; Whitesides, G. M. Chem. Rev. 1994, 94, 2383.

16. Estimation of the void volume either based on the channel dimensions or using the stoichiometry of methanol clathrate, the calculated density, and the density of methanol affords similar results.

17. (a) Prince, R. B.; Saven, J. G.; Wolynes, P. G.; Moore, J. S. J. Am. Chem. Soc. 1999, 121, 3114. (b) Appella, D. H.; Christianson, L. A.; Karle, I. L.; Powell, D. R.; Gellman, S. H. J. Am. Chem. Soc. 1999, 121 , 6206 and references cited therein. 